\title{
Determination of factors affecting relapse of vaginitis among reproductive-aged women: An experimental study
}

\author{
Roxana Parsapour ${ }^{1}$, Fereshteh Majlessi ${ }^{2}$, Abbas Rahimiforoushani ${ }^{3}$, Roya Sadeghi ${ }^{4}$
}

${ }^{1}$ Ph.D. Candidate of Health Promotion and Health Education, Department of Health Promotion and Health Education, School of Public Health, Tehran University of Medical Sciences, Tehran, Iran

${ }^{2}$ Professor, Department of Health Promotion and Health Education, School of Public Health, Tehran University of Medical Sciences, Tehran, Iran

${ }^{3}$ Professor, Department of Biostatistics and Epidemiology, School of Public Health, Tehran University of Medical Sciences, Tehran, Iran

${ }^{4}$ Associated Professor, Department of Health Promotion and Health Education, School of Public Health, Tehran University of Medical Sciences, Tehran, Iran

\section{Type of article: Original}

\begin{abstract}
Introduction: Vaginitis is a common problem for women, especially in reproductive-aged women. It is a worldwide health problem with many side effects but could be prevented by a health-promoting lifestyle related to vagina health. The aim of this study was to determine the factors affecting relapse of vaginitis.

Methods: In this experimental study, 350 reproductive-aged women with vaginitis were selected from 10 health centers in Kermanshah (Iran) during 2015 and were equally included in the intervention and control groups. To collect data, a researcher-created questionnaire, which included sociodemographic and health-promoting lifestyle questions, was used. The educational intervention was performed over 20 sessions, each lasting 25-35 minutes. An intervention group was educated by face-to-face education, pamphlets, phone contacts, text messages, and social media. Another group continued the routine clinic education and treatment without contacting the intervention group. Data were analyzed through chi-square and a logistics regression model using IBM-SPSS version 20.

Results: The results of the study indicated a significant relation between sociodemographic characteristics such as women and their husbands' literacy, job, family size, income, area for each member of family, tendency of pregnancy, body mass index $(\mathrm{BMI})$, and caesarean experience $(\mathrm{p}<0.001)$ and vaginitis. In addition, significant relationships between health-promoting lifestyle dimensions and prevention of vaginitis were identified. Relapse after intervention in the intervention group was $27.7 \%$ and $72.3 \%$ in the control group. According to the logistic regression analysis, chance for relapse of vaginitis in the group that did not receive intervention was more than the same chance in the intervention group $(\mathrm{OR}=5.14)$.

Conclusion: Health-promoting lifestyle intervention influences prevention of vaginitis. Health-promoting lifestyle, literacy promotion, prevention of caesarian, and obesity are beneficial to improvement in lifestyle dimensions associated with vagina health could be implemented as a successful prevention method. Therefore, it seems that applying a health-promoting lifestyle is essential for a healthy vagina and prevention of vaginitis.

Keywords: Relapse of vaginitis, Reproductive-aged women, Health promotion, Lifestyle
\end{abstract}

\section{Introduction}

\subsection{Background and study logic}

Most women have had vaginitis at some point in their lives (1). Vaginitis is the most prevalent infection in the genital tract and is recognized among women in the primary health care sector and in gynecology clinics. It has been

\section{Corresponding author:}

Professor Dr. Fereshteh Majlessi, Department of Health Promotion and Health Education, Faculty of Health Sciences, Tehran University of Medical Sciences, Tehran, Iran.

Tel: +98.2188989134, Fax: 0098.21 88989129-42933072, Email: dr_f_majlessi@yahoo.com

Received: April 19, 2016, Accepted: July 12, 2016, Published: January 2017

iThenticate screening: July 12, 2016, English editing: September 10, 2016, Quality control: October 25, 2016

(C) 2017 The Authors. This is an open access article under the terms of the Creative Commons Attribution-NonCommercialNoDerivs License, which permits use and distribution in any medium, provided the original work is properly cited, the use is non-commercial and no modifications or adaptations are made. 
estimated that vaginal infections alone account for $>10 \%$ of outpatient visits to providers of women's health (2). Vaginitis is a general term that refers to inflammation of the vaginal wall generally caused by one of three disorders: yeast infections, bacterial vaginosis, and trichomoniasis $(3,4)$. They affect women of all ages, but they are most common during the reproductive years (The American College of Obstetricians and Gynecologists, August 2011) The subpopulation of women (less than 10\%) suffers from recurrent often intractable episodes (5). Nearly $75 \%$ of all adult women have had at least one yeast infection in their lifetime, and 40 to 45 percent will have two or more (6-9). Vaginitis is a global health problem that affects men, women, families, and communities. It may have severe consequences such as infertility, ectopic pregnancy, chronic pelvic pain, abortion, and an increased risk of HIV transmission, preterm birth or delivery of a low-birth weight infant. Therefore, proper prevention and treatment of these diseases are of great importance $(8,10-15)$. Some predisposing factors for vaginitis include obesity, physical activity deficiency, high intake of sugar, carbohydrates, cola and alcohol, low intake of dairy products, low Vitamin $\mathrm{C}$, stress, sleep disorders, and antibiotics, consequently reducing simple carbohydrates and refined foods (4). Nutrient intake may be associated with vaginitis. For example, dietary fiber, fruits, and vegetables (16). Too much sugar is also found to be bad for vaginal health and can make one more prone to yeast infections. Therefore a strict low-carb diet is recommended $(15,20)$. If women want to enjoy having a healthy vagina, they should stick with a balanced diet, avoid processed and sugar-rich foods and eat plenty of fresh vegetables and fruits $(19,20)$. Increased psychosocial stress is associated with greater bacterial vaginosis prevalence, recurrent candida vulvovaginitis, and incidences independent of other risk factors $(7,17)$. According to the above, lifestyle is associated with vaginitis. The term "lifestyle" is a theory that is often used to refer to the way people live (21). Lifestyle includes behaviors such as food habits, sleeping and resting, physical activity and exercising, weight control, smoking and alcohol consumption, immunization against disease, coping with stress and ability to use family and society supports (19). The WHO defines health promotion as the process of enabling people to increase control over and to improve their health (WHO, 1986). Health-promoting lifestyles refer to individual actions to attain positive health outcomes (Pender, Murdaugh, \& Parsons, 2011 [22]). Pender classified health-promoting lifestyles in six dimensions: nutrition, physical activity, stress management, interpersonal relationships, spiritual growth, and health responsibility $(23,24)$. Maintaining health typically requires improvement in health-promoting lifestyles $(25)$. Women are the primary health promoters all over the world. For their effective participation in health promotion, women require access to information, networks, and funds (26). Women's health is the fundamental component of development and improvement in the developing world (27). Regarding the increase in prevalence genecology tract infections in various communities, WHO often emphasizes their prevention and control. The necessity of consultation and education for efficient preventive healthy behaviors is one of the hottest topics in sexual and reproductive health. Education of women at the reproduction age toward infection prevention, using health services and self-care methods aimed at reduction of disease transmission and treatment, is a necessity in society $(10,28)$.

\subsection{Objectives}

The main objective of this current research was to determine factors affecting vaginitis and relapse of this disease among reproductive-aged women. The specific objectives were to determine the difference between the intervention group and control group to assess the effect of a health-promoting lifestyle on vaginitis. We tried to empower women's lifestyles by educational intervention concentrated on three main dimensions: nutrition behaviors, physical activity, and mental health.

\section{Material and Methods}

\subsection{Research design and setting}

This experimental study was conducted on 350 reproductive-aged women with diagnosed vaginitis in health centers affiliated to Kermanshah University of Medical Sciences (a city in west Iran) during 2015. Patients were divided into intervention and control groups. The intervention group $(\mathrm{n}=175$ participated in a health-promoting lifestyle designed education based on the adopted Pender's health promotion model of additional routine treatment; the control group $(n=175)$ received routine treatment. The tool for gathering data was a researcher-made questionnaire administered for all 350 participants in the beginning of the study and six months after intervention.

\subsection{Sample size and Sampling method}

The sample size with a $95 \%$ confidence level and power of $80 \%$ was calculated $137.5(\sim 140)$ by considering the $\mathrm{OR}=1.7, \mathrm{P}=0.45$ (relapse of vaginitis according epidemiology of vaginitis), and $\mathrm{L}=\operatorname{Ln}(1.7)=0.53$. By hypothesis based on $20 \%$ abscission, 175 patients were considered in each group. It was a stratified two-stage clustered sampling. The health centers in Kermanshah (a total of 24 centers) were considered as clusters. Then health centers were stratified in five geographic areas (north, south, east, west, and center) of the city. In the first stage for each 
stratum, two health centers were selected randomly (10 centers), in the second stage from each selected health center, women with vaginitis were selected randomly.

\subsection{Participant allocation}

The 10 centers were named on 10 cards. These cards were scrambled, and each time one card was picked out, it was considered as an intervention center, and the next card was associated with the control center. Therefore, five health centers were allocated for the intervention group and five centers for the control group.

\subsection{Experiment and data collection}

To collect data, a researcher-created questionnaire included sociodemographic questions (age, literacy, job, husband's job, husband's literacy, economic statues, area for each member of family, BMI, history of abortion, history of vaginitis, caesarean, and family size); the second part of questionnaire included questions about lifestyle, which were designed in three dimensions (nutrition behaviors, physical activity, and mental health) with a multiple Likert scale range of choices being used. Although there are some questionnaires such as Walker's health-promoting lifestyle profile, there is no questionnaire about lifestyle related to vagina health. Consequently, the questionnaire to measure lifestyle related to vagina health was designed and validated via psychometric process. After randomly selecting and dividing clinics into intervention and control groups, the control group received the usual treatment, and the intervention group received health-promoting lifestyle education emphasized in three dimensions: nutrition behaviors, physical activity, and mental health additional routine treatment. Content of intervention adapted to women's needs in three aspects of lifestyle associated with vagina health and prevention vaginitis. The intervention was performed over 20 sessions in 20 to $30 \mathrm{~min} \neg$ ute increments. Face-to-face education, pamphlets, phone contacts, text messages, and social (Internet) media followed the intervention group.

\subsection{Statistical analysis}

To approach the aims of the research and answer the questions, data were analyzed by IBMC SPSS $\odot$ Statistics version 20 (IBMC Corp., Armonk, NY, USA) using tests including chi-squares test, and logistic regression ( $<$ 0.05 ) was considered a statistically significant level. The confidence interval was $95 \%$.

\subsection{Study variables, bias, and confounders}

Health-promoting lifestyle was the intervention variable, and relapse of vaginitis was considered the outcome. Because centers were randomized into two groups in this study, it is expected that most of the biases were adjusted. The intervention group and control group had no contact with each other. To avoid bias, Kermanshah health centers were requested not to allow any other similar intervention to be conducted during the time this research was carried out.

\subsection{Research ethics}

The research project received the confirmation of the Institution Ethics Committee of Tehran University of Medical Sciences (number 9021108004-133603, dated 12/30/2015). All required arrangements were done. Participants were intimated with details of the study, asked to read and sign a consent form, and assured of confidentiality. The women volunteers were given the opportunity to leave the study if they became uncomfortable. The control group was given the opportunity to participate in the health-promoting educational program after the study. All questionnaires was completed in privacy and in a comfortable room in the health centers after receiving routine treatment by patients in the office. A total of 350 of participant were assured the information would remain private.

\section{Results}

The mean age of women in this study was $31.03 \pm 7.65$ years. Most of our study population $(93.1 \%)$ consisted of housewives. The financial status of participants was moderate (88.9\%). Mean of literacy years in these women was $8.89 \pm 3.65$ and $9.94 \pm 3.54$ in their husbands. Mean of BMI 26.84 \pm 3.61 . Most (68.3\%) participants were living in families with three or four members. Demographic variables were not significantly different between two groups. Other features of women participating in the study based on intervention and control groups are shown in (Table 1). Eighty-eight percent of all participants had vaginitis at least once in six months before the study: $51.3 \%$ in the intervention group and $48.7 \%$ in the control group. Although there is not any difference between groups before intervention, we noted a correlation between participants' lifestyle and relapse of vaginitis. Relapse of vaginitis in the intervention group is $17.7 \%$ and $46.3 \%$ in the control group. Chi-square tests show a significant $(\mathrm{p}<0.001)$ relation between intervention and relapse of vaginitis (Table 2). 
http://www.ephysician.ir

Table 1. Sociodemographic Characteristics of Participant in Two Groups

\begin{tabular}{|c|c|c|c|c|}
\hline \multirow{2}{*}{\multicolumn{2}{|c|}{ Characteristics }} & \multicolumn{2}{|l|}{ Groups } & \multirow[t]{2}{*}{$P$-value } \\
\hline & & Intervention $(n=175)$ & Control $(n=175)$ & \\
\hline \multicolumn{2}{|l|}{ Age (year) } & $30.08 \pm 7.61$ & $30.99 \pm 7.70$ & 0.26 \\
\hline \multicolumn{2}{|l|}{ Literacy } & $9.11 \pm 3.60$ & $8.67 \pm 3.70$ & 0.25 \\
\hline \multicolumn{2}{|l|}{ Husband literacy } & $10.05 \pm 3.50$ & $9.84 \pm 3.59$ & 0.57 \\
\hline \multicolumn{2}{|l|}{ Settlement area } & $117.26 \pm 40.61$ & $119.40 \pm 43.78$ & 0.63 \\
\hline \multicolumn{2}{|l|}{ Area per person in family } & $31.24 \pm 11.75$ & $32.10 \pm 13.04$ & 0.51 \\
\hline \multicolumn{2}{|l|}{ Weight $(\mathrm{kg})$} & $69.39 \pm 10.95$ & $69.65 \pm 10.70$ & 0.82 \\
\hline \multicolumn{2}{|l|}{ Height $(\mathrm{cm})$} & $160.91 \pm 5.33$ & $160.61 \pm 5.44$ & 0.59 \\
\hline \multicolumn{2}{|l|}{$\operatorname{BMI}\left(\mathrm{kg} / \mathrm{m}^{2}\right)$} & $26.72 \pm 3.51$ & $26.97 \pm 3.71$ & 0.52 \\
\hline \multirow[t]{3}{*}{ Job } & Housewife & $162(93.6 \%)$ & $160(92.5 \%)$ & \multirow[t]{3}{*}{0.89} \\
\hline & Occupied (worker, employee) & $8(4.6 \%)$ & $9(5.2 \%)$ & \\
\hline & Student & $3(1.7 \%)$ & $4(2.3 \%)$ & \\
\hline \multirow[t]{4}{*}{ Husband job } & Unemployed, jobless & $6(3.5 \%)$ & $7(4 \%)$ & \multirow[t]{4}{*}{0.98} \\
\hline & Occupied (worker, employee) & $156(90.7 \%)$ & $158(90.3 \%)$ & \\
\hline & Retired & $6(3.5 \%)$ & $5(2.9 \%)$ & \\
\hline & Student, collegian & $4(2.3 \%)$ & $5(2.9 \%)$ & \\
\hline \multirow[t]{3}{*}{ Financial status } & Good & $12(6.9 \%)$ & $10(5.7 \%)$ & \multirow[t]{3}{*}{0.09} \\
\hline & Moderate & $155(88.6 \%)$ & $156(89.2 \%)$ & \\
\hline & $\mathrm{Bad}$ & $8(4.6 \%)$ & $9(5.1 \%)$ & \\
\hline \multirow[t]{5}{*}{ Family size } & Two & $9(5.3 \%)$ & $10(5.8 \%)$ & \multirow[t]{5}{*}{0.13} \\
\hline & Three & $56(32.2 \%)$ & $65(37.6 \%)$ & \\
\hline & Four & $69(39.7 \%)$ & $47(27.2 \%)$ & \\
\hline & Five & $22(12.6 \%)$ & $33(19.1 \%)$ & \\
\hline & Six and more & $18(10.3 \%)$ & $18(10.3 \%)$ & \\
\hline \multirow[t]{4}{*}{ Vaginitis recurrence history } & No & $17(9.7 \%)$ & $25(14.3 \%)$ & \multirow[t]{4}{*}{0.27} \\
\hline & Once & $65(37.1 \%)$ & $72(41.1 \%)$ & \\
\hline & Two times & $72(41.1 \%)$ & $56(32.6 \%)$ & \\
\hline & Three times and more & $21(12 \%)$ & $22(12.57 \%)$ & \\
\hline
\end{tabular}

Table 2. Chi-Square tests between groups

\begin{tabular}{|l|l|l|l|l|}
\hline \multirow{2}{*}{ Variable } & \multicolumn{3}{|l|}{ Before intervention } & \multicolumn{2}{l|}{ After intervention } \\
\cline { 2 - 5 } & Intervention group & Control group & Intervention group & Control group \\
\hline Without relapse & $17(40.5 \%)$ & $25(59.5 \%)$ & $144(60.5 \%)$ & $94(39.5 \%)$ \\
\hline Relapse & $158(51.3 \%)$ & $150(48.7 \%)$ & $31(27.7 \%)$ & $81(72.3 \%)$ \\
\hline Value & 1.732 & 32.826 & \\
\hline df & 1 & 1 & \\
\hline P-value & 0.249 & $<0.001$ & \\
\hline
\end{tabular}

Chi-square test results in Table 3 indicate a relation between relapse of vaginitis and some socioeconomic characteristic such as women and their husbands' literacy, job, family size, income, area allocated for each member of the family, tendency of pregnancy, BMI, caesarean history, and experience of health education about healthpromoting lifestyle associated with vaginitis $(\mathrm{p}<0.001)$. In addition, the same results (Table 4) addressed a significant relationship between health-promoting lifestyle and vaginitis; these included nutrition behaviors, physical activity, mental health, genital health, social support and interpersonal relationships, responsibility for health, selfefficacy, benefits and barriers of health-promoting lifestyle and role of health providers. Chi-square tests showed a significant relationship between all health-promoting lifestyle dimensions and prevention of vaginitis. Independent variables were included in the logistic regression. In this model, odds ratio and confidence intervals are shown for the variables that resulted in significant P-value. Logistic regression shows the chance of vaginitis in different groups of participants. According to the logistic regression analysis, in regard to factors that were positively associated with relapse of vaginitis, chance for relapse of vaginitis in the group that did not receive intervention is $(\mathrm{OR}=5.14)$ times more than the same chance in the intervention group, 95\% CI (confidence interval) is 2.79-9.44. Women who were in the primary level of education (under seven years education) and who had 7-12 years 
education, respectively, had $(\mathrm{OR}=1.77$ and 2.33) times of the same chance for women who had a university education. Literacy of their husbands was significantly related to vaginitis as well. Women who had husbands under seven year's education had a 3.25 times chance more than women who had a husband with a university education, and relapse of vaginitis in women who had a husband with (7-12) years education was 1.71 times more than highlevel education (more than 12 years education). Findings showed that the chance for those in bad economic situations was ( $\mathrm{OR}=2.17,95 \%$ CI: $0.52-8.89)$ times, and women who were in moderate economic statues $(\mathrm{OR}=1.39$, 95\% CI: $0.706-2.74)$ times of the chance for women who were in good economic situations. In regards to family size associated with relapse of vaginitis, the chance for more than six members in a family was $(\mathrm{OR}=2.12,95 \% \mathrm{CI}$ : 0.74-5.99) times, and in family that had five members it was $(\mathrm{OR}=1.74,95 \%$ CI: 0.704-4.315) times the same chance in a family with three members. Chances in women with more than one caesarean history $(\mathrm{OR}=1.53,95 \%$ CI: 0.629-3.77) times the chance for the same women without caesarean. Change in BMI has been associated with relapse of vaginitis. Women who had increasing weight gain over six months or who stabilized their weight had more chance for vaginitis. Chances for women with increasing BMI was (OR=12.85, 95\% CI: 5.21-31.69) times the same chance for women who decreased their weight. Women who had no changes in their weight and kept their weight the same as six months ago as overweight $(\mathrm{OR}=3.45,95 \% \mathrm{CI}: 1.71-6.99)$ more than women who decreased their weight.

Table 3. Chi-Square tests between sociodemographic characteristics and relapse of vaginitis

\begin{tabular}{|l|l|l|l|}
\hline Sociodemographic characteristics & Value & df & $P$-value \\
\hline Groups & 32.82 & 1 & $<0.001$ \\
\hline Age & 3.42 & 2 & 0.18 \\
\hline Job & 2.81 & 1 & 0.09 \\
\hline Husbands' job & 3.013 & & 0.21 \\
\hline Literacy & 13.58 & 2 & 0.001 \\
\hline Husbands' literacy & 12.72 & 2 & 0.002 \\
\hline Income (financial statues) & 8.672 & 2 & 0.013 \\
\hline Area for each member of family & 14.68 & 3 & 0.002 \\
\hline Family size & 6.69 & 3 & 0.08 \\
\hline Caesarean & 9.50 & 2 & 0.009 \\
\hline Number of pregnancy & 6.55 & 5 & 0.21 \\
\hline Number of live child birth & 1.96 & 3 & 0.58 \\
\hline Number of abortion & 0.96 & & 0.59 \\
\hline Number of death birth & 0.65 & 1 & 0.41 \\
\hline Type of contraception & 7.95 & & 0.22 \\
\hline Tend to pregnancy & 3.96 & 1 & 0.04 \\
\hline BMI before intervention & 15.34 & & 0.001 \\
\hline BMI after intervention & 52.26 & & $<0.001$ \\
\hline Change in BMI & 52.68 & 2 & $<0.001$ \\
\hline Have an under two years infant after intervention & 0.04 & 1 & 0.82 \\
\hline Breast feeding after intervention & 0.24 & 1 & 0.62 \\
\hline Diagnosed vaginitis & 4.70 & & 0.31 \\
\hline
\end{tabular}

Table 4. Chi-Square tests between health promotion lifestyle dimension and relapse of vaginitis

\begin{tabular}{|c|c|c|c|}
\hline Health promoting lifestyle dimensions & Value & df & $P$-value \\
\hline Nutrition behaviors & 110.77 & 2 & \multirow[t]{10}{*}{$<0.001$} \\
\hline Physical activities & 101.58 & 2 & \\
\hline Mental health & 105.25 & 2 & \\
\hline Genital health & 183.64 & 2 & \\
\hline Social supports and relationships & 161.36 & 2 & \\
\hline Health providers role & 90.56 & 2 & \\
\hline Responsibility for health & 134.08 & 2 & \\
\hline Benefits of health-promoting lifestyle & 156.15 & 2 & \\
\hline Barriers of health-promoting lifestyle & 132.64 & 2 & \\
\hline Self-efficacy & 204.46 & 2 & \\
\hline
\end{tabular}


Results of binary logistic regression about relationships between health-promoting lifestyle dimensions and relapse of vaginitis show participants in the study who have weak nutrition behaviors (OR=2.61, 95\% CI: 0.33-20.62) times the same chance in women with good health-promoting nutrition behaviors. Women who were in a moderate level of health-promoting nutrition behaviors $(\mathrm{OR}=1.36,95 \% \mathrm{CI}: 0.19-9.68)$ times the same chance in women in a good level. The chance of vaginitis in women with weak physical activities (OR=7.81, 95\% CI: 1.65-36.92) times the same chance in women with good physical activities. Women who were in a moderate level of physical activities $(\mathrm{OR}=1.25,95 \% \mathrm{CI}: 0.26-5.96)$ times the same chance in women with health promoting physical activities. Chance for relapse of vaginitis in the group in a weak level of genital health $(\mathrm{OR}=0.11,95 \% \mathrm{CI}$ : 0.76-158.62) times the same chance in women with good genital health. Women in a moderate level of genital health $(\mathrm{OR}=2.46,95 \% \mathrm{CI}$ : 0.25-23.60) times the same chance in women with good genital health. Social supports and good interpersonal relationships with others were factors associated with vaginitis; logistic regression has shown the chance of vaginitis in women who have weak social supports $(\mathrm{OR}=1.82,95 \% \mathrm{CI}: 0.122-27)$ times the same chance in women in the reference group. Relapse of vaginitis in women who were in a moderate level of social support had three times the same chance in women with a good level of social support and interpersonal relationships. Women who received weak services of health providers had 1.53 times more than the reference group a chance for vaginitis. Women in a moderate level $(\mathrm{OR}=2.03 .95 \% \mathrm{CI}$ : 0.31-13.02) times the same chance in women who had received good services from health providers. The chance for vaginitis in the group who had weak responsibility about health $(\mathrm{OR}=9.02$, 95\% CI: 1.60-50.83) times the same chance in women with good responsibility about health. Women in a weak level of perceived benefits of health-promoting lifestyle had more chances for relapse of vaginitis; the chance for vaginitis in this group $(\mathrm{OR}=23.33,95 \% \mathrm{CI}: 2.21-24.60)$ times the same chance in women who had a good perception about the benefits of a health-promoting lifestyle. Also the chance of vaginitis in the moderate group $(\mathrm{OR}=7.67,95 \% \mathrm{CI}: 0.87-67.23)$ times the same chance in the reference group. Women in a moderate level of perceived barriers for health-promoting lifestyle had more chance for relapse of vaginitis; the chance for vaginitis in this group $(\mathrm{OR}=1.68,95 \% \mathrm{CI}: 0.26-10.99)$ times the same chance in women who had a good perception about barriers for a health-promoting lifestyle. Women in a weak level of self-efficacy had more chance for vaginitis $(\mathrm{OR}=11.25,95 \% \mathrm{CI}: 1.17-10.79)$ times the same chance in women who had good self-efficacy.

\section{Discussion}

This study addressed a significant relationship between prevention of vaginitis or relapse of it, and a healthpromoting lifestyle that included proper nutrition behaviors, physical activity, mental health, genital health, social supports and interpersonal relationships, responsibility for health, self-efficacy, perceived benefits, and barriers of a health-promoting lifestyle and role of health providers. Also the finding of this study indicated a significant relation between relapse of vaginitis and socioeconomic characteristics (women and their husbands' literacy, job, family size, financial status, area for each member of family, tendency of pregnancy, BMI, and caesarean experience). Review of the literature about vaginitis shows that lifestyle is associated with vaginitis. For example, nutrition behaviors such as sugar, dairy, vegetable, and fruit intake; physical activity leads to weight control; BMI; stress, also mental health including relationships with others, problem-solving skills, perception of counseling, and acceptance of responsibility about health are relate to vaginitis. Therefore, three aspects of lifestyle-nutrition behaviors, physical activity, and mental health-were the most important subjects in our intervention. Results of this study indicate the positive effect of health-promoting intervention on reproductive-age women's health and concordances to the results of the study conducted by Abbas Rahimi Foroushani et al. (29). There have been surveys in Kermanshah about vaginitis and the need for implementation of an educational intervention (30). Thus design of intervention adjusted an understanding of the problem and the context (31). According to the rising scores of lifestyle dimensions for patients who received intervention, quality of life has improved in these women. This indicates that intervention is necessary for women, as Sneha Barot has said: Investment in sexual and reproductive health is necessary to reach ideal global health (32). Other studies showed treatment and behavioral intervention programs are effective methods of treatment, but the behavioral intervention program is superior and cost-effective with few side effects (33). Lifestyle factors are related to many diseases that could be prevented through exercise, good nutrition, avoidance of tobacco and alcohol, psychological well-being and healthy interpersonal relationships, relaxation, stress management, suitable sleeping, spiritual involvement, spending time in nature, and service to others, says Dr. Roger Walsh of the University of California, Irvine's College of Medicine and Michael O'Donnell (34). In the nutrition field, routine diary fresh vegetables and fruits intake reduce the chance to get vaginitis, whereas sweets intake increases probability of vaginitis (35). In Watson and Calabretto's study, as in our study, the vaginal inflammation in the group that used yoghurt was decreased up to three times. Keeping a balanced diet and nutritional considerations are vital for women. In addition, inadequate physical activities lead to obesity, which is a susceptible factor for vaginitis. Implement of 30-minute simple exercises and walking three to five times per week 
enabled women to achieve normal BMI and prevent obesity. A study conducted by Baheiraei et al. on women of reproductive age in Tehran reveals that physical activity makes positive changes in health. These studies have reported the relationship between self-efficacy and the subdomains of health-related lifestyles such as nutrition, physical activity, health responsibility, and other subdomains (36). Also in our study, we tried to raise self-efficacy in simple ways. Patients learned to keep to their routine activities even in dusty and warm weather. They were able to engage in simple physical activities at home; they also arranged their diet in simple and cost-benefit methods. In this study, we could improve female scores in mental health settings because we believe it is an important aspect of lifestyle related to vagina health, as noted by Fiocco (37). Further, Mojgan Mirghafourvand et al., in a study of health-promoting behaviors and their predictors in Iranian women of reproductive age (36), and Jiang et al. (2007) have similar findings in their intervention (38). Women in this study learned how to overcome stress by pursuing relaxing activities such as meditation, breathing slowly and deeply, doing regular exercises, listening to music, and maintaining communication with others, especially relatives, as different ways to manage stress. This was in line with the results of the Dale et al. study. Adequate sleep is a major component of women's health. Determining regular hours for sleeping and having a daily program for walking also could promote the quality and quantity of sleeping were also learned by women, according to Abedi et al. in their study $(39,40)$. The results showed that the health-promoting educational intervention largely reduces relapse of vaginitis and promoted lifestyle of women. It is our recommendations for future action for the implementation of other surveys about reproductive health, especially vaginitis and behavioral factors such as sexual behaviors that we tried to follow. According to our findings, the intervention revealed that the intervention could be delivered with fidelity and was acceptable to patients (41). There is no doubt that it will be beneficial, in which case it should be implemented. Finally, the effects of the intervention are sufficiently promising. In that case, the researcher who understands the underlying problem has developed a credible intervention and considered that the key points in evaluation will be in a strong position in which to conduct a worthwhile, rigorous, and achievable definitive trial, as Campbell et al. noted in 2007 (42).

\section{Conclusions}

This study helped us to determine important factors associated with vagina health, prevention of vaginitis, and relapse of this issue. The findings of this study showed a significant relationship between lifestyle and vaginitis. In addition, there is a significant relationship between some sociodemographic characteristics (women and their husbands' literacy, job, family size, financial status, tendency of pregnancy, and caesarean experience) and vaginitis. The importance of these outputs is to apply health-promoting lifestyle intervention adjusted to the context concentrated on target groups, especially housewives, couples in low levels of literacy and financial status, and prevention of caesareans as an innovated protocol for prevention of vaginitis and relapse of this disease in primary health care services.

\section{Acknowledgments:}

This study was part of a $\mathrm{PhD}$ thesis at the Tehran University of Medical Sciences. This research project was partially sponsored by Tehran University of medical sciences (grant number 28201). We gratefully acknowledge the support and generosity of Tehran University of Medical Sciences. We thank Kermanshah University of Medical Sciences for support and for allowing us to work on health centers affiliated with the university and use of their facilities for educational intervention, gathering data, and contacting patients. The authors also would like to offer special thanks to all health provider staff in the Kermanshah governmental health centers who participated in this study. The authors would like to thank and express their gratitude to expert panels, especially the academic board of the department of health promotion and health education in the Public Health School as well as 10 gynecologists of Tehran University of Medical Sciences that helped us during the research.

\section{Conflict of Interest:}

There is no conflict of interest to be declared.

Authors' contributions:

All authors contributed to this project and article equally. All authors read and approved the final manuscript.

\section{References:}

1) Kimberly A Workowski, Stuart Berman. Sexually transmitted diseases treatment guidelines. Centers for Disease Control and Prevention (CDC). 2015; 64(3): 1-137.

2) Karaer A, Boylu M, Avsar AF. Vaginitis in Turkish women: symptoms, epidemiologic-microbiologic association. Eur J Obstet Gynecol Reprod Biol. 2005; 121(2): 211-5. doi: 10.1016/j.ejogrb.2004.11.030. PMID: 16054964. 
3) Karasz A, Anderson M. The vaginitis monologues: women's experiences of vaginal complaints in a primary care setting. Soc Sci Med. 2003; 56(5): 1013-21. PMID: 12593874.

4) Gor HB, Rivlin ME. Vaginitis Treatment \& Management. Medscape. 2015.

5) Tempera G. Vaginal infections: epidemiology and risk factors. Giorn It Ost Gin. 2005; 7-8.

6) Koumans EH, Sternberg M, Bruce C, Mc Quillan G, Kendrick J, Sutton M, et al. The prevalence of bacterial vaginosis in the United States, 2001-2004; associations with symptoms, sexual behaviors, and reproductive health. Sex Transm Dis. 2007; 34(11): 864-9. doi: 10.1097/OLQ.0b013e318074e565. PMID: 17621244.

7) Al-Aali KY. Prevalence of Vaginal Candidiasis among Pregnant Women Attending Al-Hada Military Hospital, Western Region, Taif, Saudi Arabia. IJSR. 2015; 4(5).

8) Centers for Disease Control and Prevention. Genital/vulvovaginal candidiasis statistics. Retrieved March 27, 2012. Available from: http://www.cdc.gov/disease/candidiasis/genital/statistics.html)

9) Sutton M, Sternberg M, Koumans EH, McQuillan G, Berman S, Markowitz L. The prevalence of Trichomonas vaginalis infection among reproductive-age women in the United States, 2001-2004. Clin Infect Dis. 2007; 45(10): 1319-26. doi: 10.1086/522532. PMID: 17968828.

10) Prospero FD. Focus on candida, trichomonas, bacteria and atrophic vaginitis.

11) WHO. Sexually transmitted and other reproductive tract infections: a guide to essential practice. 2005.

12) World Health Organization (WHO). Sexually Transmitted Infections (STIs): the importance of a renewed commitment to STI prevention and control in achieving global sexual and reproductive health. 2013.

13) Hafner LM, Pelzer ES. Tubal damage, infertility and tubal ectopic pregnancy: chlamydia trachomatis and other microbial etiologies: INTECH Open Access Publisher. 2011.

14) Xia DY, Liao SS, He QY, Choi KH, Mandel JS. Self-reported symptoms of reproductive tract infections among rural women in Hainan, China: prevalence rates and risk factors. Sex Transm Dis. 2004; 31(11): 643-9. doi: 10.1097/01.olq.0000143111.33741.40. PMID: 15502670.

15) Msuya SE, Mbizvo E, Stray-Pedersen B, Sundby J, Sam NE, Hussain A. Reproductive tract infections and the risk of HIV among women in Moshi, Tanzania. Acta Obstet Gynecol Scand. 2002; 81(9): 886-93. doi: 10.1034/j.1600-0412.2002.810916.x. PMID: 12225308.

16) Hillier SL, Nugent RP, Eschenbach DA, Krohn MA, Gibbs RS, Martin DH, et al. Association between bacterial vaginosis and preterm delivery of a low-birth-weight infant. The Vaginal Infections and Prematurity Study Group. N Engl J Med. 1995; 333(26): 1737-42. doi: 10.1056/NEJM199512283332604. PMID: 7491137.

17) Neggers YH, Nansel TR, Andrews WW, Schwebke JR, Yu KF, Goldenberg RL, et al. Dietary Intake of Selected Nutrients Affects Bacterial Vaginosis in Women. J Nutr. 2007; 137(9): 2128-33. doi: 10.1258/ijsa.2011.011012. PMID: 17709453, PMCID: PMC2663425.

18) Ehrstrom SM, Kornfeld D, Thuresson J, Rylander E. Signs of chronic stress in women with recurrent candida vulvovaginitis. Am J Obstet Gynecol. 2005; 193(4): 1376-81. doi: 10.1016/j.ajog.2005.03.068. PMID: 16202729.

19) Chapple A, Hassell K, Nicolson M, Cantrill J. 'You don't really feel you can function normally': Women's perceptions and personal management of vaginal thrush. J Reprod Infant Psychol. 2000; 18(4): 309-19. doi: $10.1080 / 713683045$.

20) Pirzadeh A, Sharifirad G, Kamran A. Healthy lifestyle in teachers. J Educ Health Promot. 2012; 1: 46. doi: 10.4103/2277-9531.104816. PMID: 23555149, PMCID: PMC3577411.

21) Sharma R, Biedenharn KR, Fedor JM, Agarwal A. Lifestyle factors and reproductive health: taking control of your fertility. Reprod Biol Endocrinol. 2013; 11: 66. doi: 10.1186/1477-7827-11-66. PMID: 23870423, PMCID: PMC3717046.

22) Feldman LP, Hornik J. The use of time: An integrated conceptual model. J Consum Res. 1981: 7(4): 40719. doi: $10.1177 / 0961463 X 96005003007$.

23) Chiou AF, Hsu SP, Hung HF. Predictors of health-promoting behaviors in Taiwanese patients with coronary artery disease. Appl Nurs Res. 2016; 30: 1-6. doi: 10.1016/j.apnr.2015.08.008. PMID: 27091244.

24) Enjezab B, Farajzadegan Z, Taleghani F, Aflatoonian A, Morowatisharifabad MA. Health promoting behaviors in a population-based sample of middle-aged women and its relevant factors in Yazd, Iran. Int J Prev Med. 2012; 3(1): 191-8. PMID: 22826765, PMCID: PMC3399308.

25) Motlagh Z, Mazloomy-Mahmoodabad S, Momayyezi M. Study of health-promotion behaviors among university of medical science students. ZJRMS. 2011; 13(4): 29-34. 
26) Tol A, Tavassoli E, Shariferad GR, Shojaeezadeh D. Health-promoting lifestyle and quality of life among undergraduate students at school of health, Isfahan University of medical sciences. J Educe Health Promote. 2013; 2: 11. doi: 10.4103/2277-9531.108006. PMID: 24083261, PMCID: PMC3778574.

27) Watt RG. Strategies and approaches in oral disease prevention and health promotion. Bull World Health Organ. 2005; 83(9): 711-8. doi: S0042-96862005000900018. PMID: 16211164, PMCID: PMC2626336.

28) Chamberlain J, Watt S, Mohide P, Muggah H, Trim K, Bantebya Kyomuhendo G. Women's perception of self-worth and access to health care. Int J Gynaecol Obstet. 2007; 98(1): 75-9. doi: 10.1016/j.ijgo.2007.03.019. PMID: 17459386.

29) Ray K, Muralidhar S, Bala M, Kumari M, Salhan S, Gupta S, et al. Comparative study of syndromic and etiological diagnosis of reproductive tract infections/sexually transmitted infections in women in Delhi. Int J Infect Dis. 2009; 13(6): 352-9. doi: 10.1016/j.ijid.2008.11.021. PMID: 19237304.

30) Rahimi Foroushani A, Estebsari F, Mostafaei D, Eftekhar Ardebili H, Shojaeizadeh D, Dastoorpour M, et al. The Effect of Health Promoting Intervention on Healthy Lifestyle and Social Support in Elders: A Clinical Trial Study. Iran Red Crescent Med J. 2014; 16(8): e18399. doi: 10.5812/ircmj.18399. PMID: 25389486, PMCID: PMC4222012.

31) Faraji R, Rahimi M, Assarehzadegan M. Prevalence of Vaginal Candidiasis infection in women referred to Kermanshah hygienic centers, Iran in 2010. Life Sci J. 2012; 9(4): 1280-3.

32) Ebrahimi Tavani M, Ghofranipour F, Hajizadeh E, Abedini M. Assessment of educational needs among women of reproductive age with common genital tract infections (vaginitis): The first step for developing a self-care educational package. IJWHR. 2015; 3(4): 201-7. doi: 10.15296/ijwhr.2015.42.

33) Barot S. Sexual and Reproductive Health and Rights Are Key to Global Development: The Case for Ramping Up Investment. Guttmacher Policy Review. 2015; 18(1): 1-7.

34) Golmakani N, Khadem N, Arabipoor A, Kerigh BF, Esmaily H. Behavioral intervention program versus vaginal cones on stress urinary incontinence and related quality of life: a randomized clinical trial. Oman Med J. 2014; 29(1): 32-8. doi: 10.5001/omj.2014.08. PMID: 24498480, PMCID: PMC3910410.

35) Zando, Escultur. W.H.O, World Health Organization 2009. Health PROMOTION, Milestones in Health Promotion Statements from Global Conferences Statements from global conferences: Geneva. World Health Organization. 2009.

36) Al-Ghazzewi FH, Tester RF. Biotherapeutic agents and vaginal health. Journal of Applied Microbiology. 2016; 121(1): 18-27. doi: 10.1111/jam.13054. Available from: http://onlinelibrary.wiley.com/doi/10.1111/jam.13054/full

37) Mirghafourvand M, Sehhati F, Rahimi M. Health-promoting Lifestyle and its Demographic Predictors in Infertile Couples Referred to Infertility Clinic of Tabriz Al-Zahra Hospital, 2013. J Caring Sci. 2014; 3(3): 175-84. doi: 10.5681/jcs.2014.019. PMID: 25276761, PMCID: PMC4171816.

38) Walker SN, Kerr MJ, Pender NJ, Sechrist KR. A Spanish language version of the health-promoting lifestyle profile. Nurs Res. 1990; 39(5): 268-73. PMID: 2399130.

39) Fiocco AJ, Scarcello S, Marzolini S, Chan A, Oh P, Proulx G, et al. The effects of an exercise and lifestyle intervention program on cardiovascular, metabolic factors and cognitive performance in middle-aged adults with type II diabetes: a pilot study. Can J Diabetes. 2013; 37(4): 214-9. 2013. doi:0.1016/j.jcjd.2013.03.369. PMID: 24070883.

40) Jiang Zm, Li Yy, Wu Jq, Li Wy, Wen Zy, Gao Es, et al. An Intervention study of reproductive tract infections among married women of reproductive age in Shanghai. Journal of Reproduction and Contraception. 2007; 18(2): 110-20. doi: 10.1016/S1001-7844(07)60014-5.

41) Dale H, Brassington L, King K. The impact of healthy lifestyle interventions on mental health and wellbeing: a systematic review. Mental Health Review J. 2014; 19(1): 1361-9322. doi: 10.5812 /ircmj. 18399 .

42) Abedi P, Jordi M, Afshari P. Evaluation of the Health Promotion Lifestyle and its Related Factors in Reproductive Aged Women in Ahvaz, Iran. J Epidemiol Community Health. 2015; 9(1). doi: 10.1136/jech2015-206800.

43) Ebrahimi Tavani M, Ghofranipour F, Hajizadeh E, Abedini M. Assessment of Educational Needs Among Women of Reproductive Age With Common Genital Tract Infections (Vaginitis): The First Step for Developing a Self-care Educational Package, International. J Womens Health. 2015; 3(4): 201-7. doi: 10.15296/ijwhr.2015.42.

44) Campbell NC, Murray E, Darbyshire J, Emery J, Farmer A, Griffiths F, et al. Designing and evaluating complex interventions to improve health care. BMJ. 2007; 334(7591): 455-9. doi: 10.1136/bmj.39108.379965.BE. PMID: 17332585, PMCID: PMC1808182. 